\title{
LA REVOLUCIÓN DIPLOMÁTICA Y LA NEGOCIACIÓN DEL MATRIMONIO ENTRE LOS PRÍNCIPES DE ASTURIAS, CARLOS Y MARÍA LUISA (1765)
}

\author{
Sergio Belmonte Hernández \\ (Universidad Complutense de Madrid) \\ sbelmont@ucm.es
}

\section{RESUMEN}

La revolución diplomática de 1756 entre Francia y el Imperio llevó a un acercamiento de Luis XV y la emperatriz María Teresa después de siglo y medio de enfrentamientos entre las Casas de Habsburgo y Borbón. La muerte de Fernando VI y la subida al trono de Carlos III supuso poner fin a la política de neutralidad del anterior reinado. La firma del tercer Pacto de Familia en 1761 llevó al monarca español a integrarse dentro de la nueva alianza surgida entre París y Versalles. Estas alianzas se sellaron, como era tradicional, a través de matrimonios entre ambas Casas, sin embargo, dentro de este contexto hubo un enlace que supuso una excepción a las nupcias entre archiduquesas Habsburgo y príncipes Borbones, se trataba de los príncipes de Asturias, futuro Carlos IV, y María Luisa de Parma.

PALABRAS CLAVE: Revolución Diplomática; Pacto de Familia; Matrimonio; Casa de Habsburgo, Casa de Borbón.

\section{THE DIPLOMATIC REVOLUTION AND THE NEGOTIATION OF MARRIAGE BETWEEN PRINCES OF ASTURIES, CHARLES AND MARIE LOUISE (1765)}

\begin{abstract}
The Diplomatic Revolution of 1756 between France and the Empire supposed an approach of Louis XV and the empress Maria Theresa after one century and half of confrontation among the Houses Habsburg and Bourbon. The death of Ferdinand VI and the accession to the crown of Charles III changed the neutrality politics of the previous reign. The Spanish monarch joined the new alliance between Paris and Vienna after the third Pacte de Famille. The alliance was sealed through marriages with members of both dynasties, nevertheless, there was a wedding that was an exception, the marriage of the princes of Asturies, future Charles IV, and Marie Louise of Parme.
\end{abstract}

KEY WORDS: Diplomatic Revolution; Pacte de Famille; Marriage; House of Habsburg; House of Bourbon. 
En 1760, la reina María Amalia falleció. Aunque cabía la posibilidad de que el monarca encontrara otra esposa, Carlos III siempre mostró su aversión a contraer matrimonio de nuevo ${ }^{1}$. El rey descartó para sí las nupcias y las comenzó a centrar en sus herederos. Sus respectivos enlaces se enmarcaron dentro del acontecer diplomático europeo, influenciado por la reversión de alianzas que se produjo en 1756 entre las principales potencias de Europa, destacando como factor clave para la Monarquía española el acercamiento entre Francia y el Imperio.

\section{LA FORJA DE LA ALIANZA FRANCO-AUSTRÍACA}

La aproximación entre las antaño antagonistas Casas de Borbón y Habsburgo tiene su origen en la firma de la paz de Aquisgrán en 1748, tras el fin de la guerra de Sucesión de Austria (1740-1748). El rey de Prusia, Federico II, se adueñó de Silesia, una de las regiones más ricas y prósperas de las posesiones de María Teresa. Su aliado, el rey Luis XV de Francia conquistó los Países Bajos austríacos e infligió una severa derrota a las tropas británicas de Jorge II, principal apoyo de la emperatriz, en la Batalla de Fontenoy en 1745. Al conquistar el monarca francés los Países Bajos, el electorado de Hannover, posesión patrimonial de los monarcas británicos, quedó a merced de las tropas francesas. Jorge II instó entonces a María Teresa a negociar la paz por todos los medios. La emperatriz alegó que no firmaría un armisticio hasta que no recuperara Silesia, conquistada por Prusia, pero el Parlamento inglés anuló los subsidios que proporcionaba a la soberana. Sin este dinero, María Teresa no podía costear el pago de sus ejércitos. Las presiones de Londres le forzaron pues a aceptar el cese de las hostilidades. A pesar de que María Teresa fue reconocida como reina de Hungría y Bohemia, y su esposo Francisco como Emperador, la nueva soberana puede ser considerada como la gran perdedora de la guerra. La emperatriz tuvo que aceptar la amputación de parte de sus estados patrimoniales como Silesia y Parma.

Consumada la Paz de Aquisgrán, Viena comenzó a cuestionarse su tradicional alianza con Gran Bretaña, existente desde la guerra de los Nueve Años. En este contexto, la emperatriz pidió a su consejo que dirimiera la posibilidad de buscar otros aliados en Europa. Entre los consejeros de la emperatriz no existió una postura clara respecto a la continuidad o no de la alianza británica. Los Harrach consideraban a Gran Bretaña como la aliada tradicional de Austria, como una potencia necesaria para contener las ambiciones francesas sobre los Países Bajos. En contra de esta opinión se manifestaba Wenzel Anton von Kaunitz-Rietberg, el consejero más joven de la emperatriz. Kaunitz entendía que Austria podía llegar a un acuerdo con Francia, cuyos ejércitos podían contribuir a neutralizar las ambiciones expansionistas de la Prusia de

\footnotetext{
${ }^{1}$ Conde de Fernán Núñez, Vida de Carlos III. Alfred Morel Fatio y Antonio Paz y Meliá, eds. (Madrid: Librería de los Bibliófilos, Fernando Fé, 1898), 290. El conde recoge que en la visita de Mariana Victoria de Portugal, hermana de Carlos III, esta tenía el propósito de ofrecer a la princesa Mariana, segunda de sus hijas, como esposa para el rey español. Sin embargo, Carlos III no quiso mudar de estado.
} 
Federico II, principal competidor de las ambiciones habsbúrgicas en Europa Central ${ }^{2}$. Ante la falta de unanimidad en los criterios de sus principales consejeros, en 1750 María Teresa decidió enviar a Kaunitz a Versalles en calidad de embajador.

El nuevo diplomático tenía como misión principal promover en la corte de Luis XV un sentimiento de afinidad hacia el Imperio. En caso de no poder convencer al gabinete francés de llegar a un acuerdo con Viena, Kaunitz aspiraba a establecer al menos unas cordiales relaciones con Francia sin que ello entrañara necesariamente el alejamiento de Gran Bretaña ${ }^{3}$. Pese a que el embajador vienés encontró en Versalles un contexto propicio para la materialización de sus ambiciones, ya que la entonces favorita de Luis XV, Madame de Pompadour, se mostró favorable a sus tesis, el diplomático abandonó Francia sin lograr concertar la deseada alianza. En cualquier caso, su fracaso fue relativo: Kaunitz había introducido en Versalles la semilla de una posible aproximación a Viena y, a su regreso a la capital austriaca, fue designado canciller por la emperatriz.

Para entonces, Prusia había iniciado conversaciones con Jorge II, lo cual desagradaba tanto a Francia como al Imperio María Teresa, a través de su nuevo embajador, Starhemberg, se comprometía a abandonar los Países Bajos y cederlos como reino a Felipe y Luisa Isabel de Borbón, yerno e hija respectivamente de Luis $\mathrm{XV}$, a cambio de los ducados de Parma, Piacenza y Guastalla. La emperatriz se ofreció además a apoyar militarmente el restablecimiento en el trono polaco de Estanislao Leczinski, cuya hija era esposa del rey francés. El Imperio también garantizaba la ayuda de Rusia, que era vital para contener a Prusia. En contrapartida, Viena demandaba a Francia que Luis XV abandonara su alianza con Federico II, y que las tropas francesas ayudaran a la emperatriz a reconquistar Silesia ${ }^{4}$. El rey francés, influido en gran medida por Madame de Pompadour y por su hechura, el abate Bernis, en aquel momento secretario de Estado de Asuntos Exteriores, se mostró favorable al acuerdo. El 1 de mayo de 1756 se producía la conocida como «revolución diplomática» ${ }^{5}$. Los Habsburgo y los Borbones, después de dos siglos de enfrentamientos, firmaban el Tratado de Versalles.

\section{ESPAÑA Y SU INSERCIÓN EN LA REVOLUCIÓN DIPLOMÁTICA}

La muerte de Felipe V en 1746 y la subida al trono de Fernando VI, hermanastro de Carlos III, entrañaron distintos cambios en la orientación de la política exterior española. El nuevo monarca se había desmarcado de Francia y de los Pactos

\footnotetext{
2 William J. McGill, “The Roots of Policy: Kaunitz in Vienna and Versailles, 1749-1753", Journal of Modern History 2 (1971): 232. Pieter M. Judson., The Habsburg Empire. A new history (Cambridge, Massachusetts, Londres: The Belknap Press of Harvard University Press, 2016), 26-27.

${ }^{3}$ Mc Gill, "The Roots", 242-244.

${ }^{4}$ Jean Paul Desprat, Le Cardinal de Bernis 1715-1794. La Belle Ambition (París: Perrin, 2000), 293-336. Sobre las condiciones de María Teresa, 318.

${ }^{5}$ Françoise Autrand, Lucien Bély, Philippe Contamine. y Thierry Lentz, eds., Histoire de la diplomatie française. I: Du Moyen Age à l'Empire (París: Perrin, 2007), 429-432.
} 
de Familia ${ }^{6}$, y tampoco tenía intención de buscar otros aliados, pues no contemplaba a Gran Bretaña como una posibilidad debido a sus ambiciones expansionistas ultramarinas. La visión del monarca y de sus ministros, Carvajal y Ensenada, era mantenerse como bloque neutral y vigilante en todos los acontecimientos y guerras que sucedieran entre las potencias europeas ${ }^{7}$. Se iniciaba así una nueva etapa que tenía por objetivos asegurar el desarrollo económico peninsular e indiano ${ }^{8}$.

El comienzo del nuevo reinado coincidió a su vez con la firma de la Paz de Aquisgrán, que puso fin a la Guerra de Sucesión Austriaca, en la que España había participado en coalición con Francia mediante el segundo Pacto de Familia suscrito en 1743. Este acuerdo había sido decepcionante para Fernando VI, pues a pesar de que se veían colmados los objetivos de conseguir Parma, Piacenza y Guastalla para el infante Felipe, en la paz se habían ignorado las pretensiones españolas sobre Gibraltar y la abolición de los derechos comerciales de Gran Bretaña en la América española. El nuevo rey tampoco vio ningún beneficio en que su hermanastro se convirtiera en duque de Parma. Las relaciones entre ambos no eran buenas, y el monarca español entendía toda esta empresa como un asunto tejido por Isabel de Farnesio, madre de don Felipe, a la cual desterró a San Ildefonso tras subir al trono. Fernando VI decidió acabar así con la política del irredentismo italiano iniciada por su padre y su madrastra?

Si Aquisgrán supuso un revés para Fernando VI, también lo fue para su otro hermanastro, Carlos. En caso de que muriera, las coronas Nápoles y Sicilia debían pasar a Felipe de Parma, por lo que su descendencia quedaba excluida de la sucesión a ambos tronos. Francia había rubricado los acuerdos sin tener en cuenta ni a España ni a Nápoles. Las relaciones entre los Borbones se enfriaron ${ }^{10}$. Luis XV, sin embargo, veía colmadas sus expectativas al satisfacer las ambiciones de su hija Luisa Isabel y de su yerno Felipe en Italia ${ }^{11}$.

${ }^{6}$ José Luis Gómez Urdáñez, Fernando VI (Madrid: Arlanza, 2001), 95-124.

${ }^{7}$ Didier Ozanam, "La Crisis de las Relaciones Hispano-Francesas a mediados del Siglo XVIII. La Embajada de Jaime Masones de Lima (1752-1761)", Tiempos Modernos 5, no. 14 (2006), http://www.tiemposmodernos.org/tm3/index.php/tm/article/view/101/134 (consultado el 5 de junio de 2020).

${ }^{8}$ José Juan Vidal y Enrique Martínez Ruíz, eds., Política interior y exterior de los Borbones (Barcelona: Tres Cantos, Istmo, 2001), 236-244.

${ }^{9}$ La política del irredentismo italiano desarrollada en el reinado de Felipe $\mathrm{V}$ siempre se ha interpretado desde la óptica de las ambiciones maternales de Isabel de Farnesio. Un ejemplo de ello es: Didier Ozanam. "Dinastía, Diplomacia y Política Exterior", en Los Borbones, Dinastía y Memoria de nación en la España del siglo XVIII, ed. Pablo Fernández Albaladejo (Madrid: Marcial Pons, 2000), 26. Sin embargo, esta tesis ya anticuada ha sido matizada por otros autores, por ejemplo: Pablo Vázquez Gestal, Una nueva majestad, Felipe V, Isabel de Farnesio y la identidad de la Monarquía (Madrid: Marcial Pons, Fundación de Municipios Pablo de Olavide, 2013), 169-251.

10 «No hubo nunca ni simpatía ni confianza entre políticos españoles y políticos franceses [...]. Éstos seguían mirándonos a menudo con suficiencia y desdén, considerando a España una potencia de menor rango que ellos». Rosa María Capel Martínez y José Cepeda Gómez, eds., El siglo de las luces, política y sociedad (Madrid: Síntesis, 2006), 282.

${ }^{11}$ Henry Sage, "Les ambitions de Louise-Élisabeth de France, duchesse de Parme, ses intrigues a la cour de Versailles", Annales de Sciences Politiques 18 (1903): 695-700. 
En cualquier caso, lo que el rey de Francia percibía como una victoria sobre María Teresa y sus aliados británicos, pronto se convirtió en un revés diplomático para el monarca. Cuando la tensión colonial en América del Norte con Gran Bretaña llegó a un punto de no retorno, Luis XV intentó por todos los medios restablecer las buenas relaciones con sus familiares Borbones. Para ello, el monarca pactó con Nápoles la mediación francesa para garantizar el acceso de los hijos de Don Carlos al trono napolitano, sacrificando así los intereses de los duques de Parma a cambio de ayuda militar ${ }^{12}$. En previsión de recuperar la amistad española, Luis XV envió al duque de Duras como embajador a Madrid. La corte madrileña se encontraba inmersa en las luchas cortesanas que intentaban decantar al rey por un bando u otro. El embajador británico Keene, con la ayuda de Wall y Carvajal, intentaba equilibrar a su favor la balanza frente a Ensenada y Duras. El poco tacto del francés en la corte fernandina y la caída de Ensenada, llevaron a que fuera retirado de la embajada, fracasando su misión de volver a incorporar a España a la alianza francesa. Cuando se produjo el estallido de la guerra de los Siete Años en 1756, a Luis XV se mostró incapaz de cambiar el parecer de Fernando VI y el gobierno español proclamó una estricta neutralidad en el conflicto ${ }^{13}$. Sin la flota hispana, Francia difícilmente podía enfrentarse a Gran Bretaña en América.

El monarca francés se veía asediado por todos los frentes. La guerra de los Siete Años contra Gran Bretaña estaba siendo desventajosa para Francia. Luis XV no podía permitirse mantener dos frentes bélicos abiertos, y el americano era francamente desfavorable para las armas francesas. Todo cambió con la subida al trono de Carlos III en 1759. Ambos monarcas, en virtud del acuerdo firmado en 1754, se aliaron mediante el Tercer Pacto de Familia ${ }^{14}$. Los Borbones volvían a unirse. Carlos III temía que, si dejaba solo a su primo, Gran Bretaña debilitaría en exceso a Francia, lo que también sería perjudicial para España. La alianza se basaba en la máxima España más Francia igual a Gran Bretaña ${ }^{15}$.

La guerra de los Siete Años fue nefasta para el nuevo bloque HabsburgoBorbón. Francia quedó como la gran potencia derrotada. El país galo cedió a Gran Bretaña todas sus posesiones en Canadá y su dominio sobre la India también se vio afectado. España perdió la Florida, aunque Francia le cedió en compensación la Luisiana. Austria tampoco consiguió recuperar Silesia, pues por el Tratado de Hubertusburgo tuvo que ceder esta posesión definitivamente a Prusia. La revolución diplomática no había conseguido frenar a los enemigos de sus creadores. No obstante, este sería el eje central de una amplia política matrimonial entre España, Francia y Austria.

\footnotetext{
12 Rohan Butler, "The secret compact of 1753 between the kings of France and Naples", en Royal and Republican Sovereignty in Early Modern Europe: Essays in memory of Ragnhild Hatton, ed. Robert Oresko, G.C. Gibbs y Hamish Scott (Cambridge: Cambridge University Press, 1997), 551-579.

${ }^{13}$ María Victoria López Cordón, "Pacte de Famille ou interets d'Etat? La monarchie française et la diplomatie espagnole du XVIIIe siècle”, en La présence des Bourbons en Europe XVIe-XXIe siècle, ed. Lucien Bély (París: Presses Universitaires de France, 2000), 190.

${ }^{14}$ Vidal y Martínez Ruíz, Politica, 272-278.

15 López Cordón, Pacte de Famille, 193.
} 


\section{LA ALIANZA FRANCO AUSTRÍACA Y LA POLÍTICA MATRIMONIAL DE CARLOS III}

La sorpresa por la alianza franco-austriaca de 1756 fue mayúscula en Europa. Federico II de Prusia no dudó en calificarla como antinatural. Para la corte española también fue algo inesperado, si bien los rumores sobre el acercamiento francoaustriaco ya se conocían en Madrid gracias al embajador Masones de Lima. En una cena dada en casa del conde de Starhemberg, y a la que fueron invitados el abad de Bernis, el diplomático español y el nuncio papal, Masones describe que después de la comida se quedó dormido, momento que aprovecharon Bernis y Starhemberg para retirarse a otra estancia a charlar. Al despertarse, el embajador intentó oír de lo que hablaban, pero no pudo escuchar más que murmullos ${ }^{16}$. Sin embargo, Masones intuía perfectamente de lo que trataba aquella conversación. Así, informaba a Wall: «Es menester verlo para creerlo, pero pudiera suceder como hemos visto que ha sucedido un terremoto general que jamás había acaecido en el mundo» ${ }^{17}$.

¿Por qué invitó a cenar el embajador imperial a los embajadores de las dos ramas más importantes de los Borbones y no a los diplomáticos que representaban a otros Estados ante la corte de Versalles? La invitación al francés estaba clara, afianzar la alianza de María Teresa con Luis XV, pero ¿y la del español? La emperatriz, al parecer, no solo quería aproximarse a Francia, también quería sondear la posible amistad con España y así alcanzar un acuerdo más amplio con la Casa de Borbón que coronara el cambio diplomático orquestado. Aquel terremoto que para Masones y sus contemporáneos fue la revolución diplomática afectaría también a España y la política matrimonial de Carlos III se vería influenciada por estos importantes cambios.

Una cuestión llamativa del Pacto de Familia suscrito entre Francia y España en 1761 es que, a diferencia de los anteriores, no se vio acompañado de alianzas matrimoniales $^{18}$, teniendo Carlos III ya en edad casadera a sus dos hijas mayores y al príncipe de Asturias. La razón estriba en que el delfín Luis José ya estaba casado y tenía una numerosa prole. Estos hijos aún eran muy pequeños, pues el mayor, Luis Augusto, apenas alcanzaba en 1761 los siete años. Las hijas de Carlos III, María Josefa y María Luisa, contaban respectivamente diecisiete y dieciséis años, por lo que urgía casarlas y no se podía esperar a que los hijos del delfín alcanzaran la edad adulta. Por otro lado, las hijas de Luis XV eran demasiado mayores para comprometerse con el príncipe Carlos, ya que la entonces primogénita, María Adelaida, era dieciséis años mayor que el heredero de la corona española. En consecuencia, Carlos III amplió las miras matrimoniales más allá de su aliada Francia, y las dirigió hacia la aliada del país galo, la Casa de Austria. Negociar los matrimonios de sus hijos con Viena no supondría ningún incidente diplomático con Francia y contribuiría a reforzar la revolución diplomática

16 Archivo Histórico Nacional (AHN), Estado, leg. 6517, s. f. Carta de Jaime Masones de Lima a Ricardo Wall, Versalles, 15 de febrero de 1756.

${ }^{17} \mathrm{AHN}$, Estado, leg. 6517, s. f. Carta de Jaime Masones de Lima a Ricardo Wall, Versalles, 2 de febrero de 1756.

${ }^{18}$ El Primer Pacto de Familia supuso la unión en 1739 del infante don Felipe y de Luisa Isabel de Borbón, y el Segundo el de la infanta María Teresa Rafaela con el delfín Luis José. 
al unirse España a esta entente. Además, también contribuirían a consolidar la posición en Italia de las ramas menores de la Casa de Borbón española (Parma, Nápoles y Sicilia). La emperatriz se mostró complacida con esta política de enlaces que ella misma también fomentó, pues en 1760 se produjo el primer matrimonio Habsburgo-Borbón al casarse el archiduque José, futuro José II, con Isabel de Parma, nieta de Luis XV y sobrina de Carlos III ${ }^{19}$.

El mismo año del fin de la guerra de los Siete Años, el monarca español concertó con María Teresa un doble matrimonio. La infanta María Luisa casaría con el archiduque Leopoldo, futuro gran duque de Toscana, enlace que se celebraría en 1765. Otro hijo del monarca, Fernando IV de Nápoles, contraería nupcias a su vez con la archiduquesa María Josefa. Sin embargo, nunca se llegó a realizar este enlace por la prematura muerte de la archiduquesa en 1767. Su lugar fue ocupado por su hermana, la archiduquesa María Carolina, cuyo matrimonio con Fernando tuvo lugar en Nápoles en $1768^{20}$. Un año después, en 1769, Carlos III volvió a negociar una nueva unión, esta vez la de su sobrino Fernando, duque de Parma, con la archiduquesa María Amalia, hija también de la emperatriz. La culminación de los matrimonios entre ambas dinastías sería el enlace en 1770 del delfín Luis Augusto, nieto de Luis XV, con la archiduquesa María Antonieta, la hija menor de María Teresa. Las ambiciones de la emperatriz se habían cumplido con creces, pues había llegado a un acuerdo pleno con todas las ramas de la Casa de Borbón que cimentaba la reversión de alianzas que ella misma había contribuido a forjar hacía más de una década. Tres de sus hijas eran respectivamente la reina de Nápoles y Sicilia, la duquesa de Parma y la delfina de Francia. La emperatriz, tras siete años de guerra que no le reportó ningún beneficio, pasó de la estrategia militar a la matrimonial y explotó hasta el último extremo el lema familiar: Bella gerant alii, tu felix Austria nube! Los descendientes de Leopoldo I y Luis XIV, enemigos declarados, pasaban del enfrentamiento a la amistad.

No obstante, una persona quedó excluida de estos enlaces. Se trataba de Carlos, príncipe de Asturias y sucesor de Carlos III. ¿Qué había llevado al monarca a dejar al heredero de la corona española fuera de todo aquel complejo esquema de alianzas matrimoniales? ¿Cómo era posible que se dejara sin casar a la figura clave que debía procurar la sucesión de la dinastía? María Teresa contaba aún con tres hijas casaderas de edades parecidas a Carlos: María Ana, María Cristina y María Isabel, si bien es verdad que la primera y la última padecían problemas de salud de distinta gravedad. Aunque Carlos III pudo pensar en unir a su hijo con alguna de ellas, al igual que había hecho con Fernando de Nápoles, eligió como candidata a la hija de su hermano Felipe, duque de Parma: María Luisa Teresa de Borbón-Parma. ¿Cómo era posible que Carlos III escogiera a una princesa de menor rango que las archiduquesas austríacas para el matrimonio del heredero de una de las monarquías más extensas del mundo? La razón es que el matrimonio del príncipe de Asturias pasaba por ser una excepcionalidad. La

${ }^{19}$ La joven no llegó a ser emperatriz pues falleció prematuramente apenas tres años después de su enlace Para una perspectiva sobre la actividad intelectual de Isabel de Borbón-Parma es capital el estudio de Elisabeth Badinter, Je meurs d amourpour toi lettres a l'archiduchesse Marie-Christine (Paris: Tallandier, 2008).

${ }^{20}$ Elisabetta De Santi Gentili, "Il viaggio verso Napoli della regina Maria Carolina d'Asburgo nel 1768: il passaggio nella Tuscia” (Tesis Doctoral, Università degli studi della Tuscia, 2002). 
elegida tendría que pertenecer a la Casa de Borbón: Carlos III primaba en este caso la endogamia familiar y elegía a una princesa por cuyas venas corría sangre borbónica ${ }^{21}$, la hija de su hermano, lo que reforzaba la vinculación de su descendencia con España ${ }^{22}$. La decisión del rey se enmarcaba, además, como indica la profesora López-Cordón, dentro de la nueva estrategia matrimonial de la Monarquía española en el siglo XVIII, según la cual las soberanas no serían seleccionadas ya en virtud exclusivamente de su capital dinástico sino de acuerdo con «objetivos diplomáticos y de equilibrio más

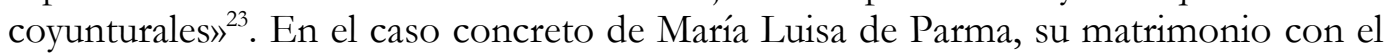
príncipe de Asturias también solucionaba dos problemas enquistados entre los diferentes titulares de la Casa de Borbón. Luis XV resarcía, de manera póstuma, la ambición de su hija Luisa Isabel de obtener un trono, y lo hacía en la persona de su nieta; por otro lado, Carlos III distinguía a su hermano Felipe eligiendo a su hija como futura reina de España, una manera de compensarlo por no haberle permitido ocupar los tronos de Nápoles y Sicilia en 1759. Las ambiciones de los duques de Parma se colmaban en su hija menor, pues la mayor, Isabel, destinada a ser emperatriz del Sacro Imperio, falleció al poco de casarse con José II.

En 1765, a pesar de los reveses en la guerra de los Siete Años, Carlos III había consolidado sus alianzas en Europa. España había entrado en la órbita franco-austriaca, y se preparaba, al igual que sus homólogas, a mostrar al mundo que todavía seguía teniendo un papel importante en la política europea. En apenas seis años el monarca había reforzado su posición, legitimado a su heredero y asegurado el matrimonio de este último. Carlos III sabía que su familia había accedido al trono por la extinción de un linaje que había gobernado durante doscientos años la Monarquía Hispánica, y quizás temía el estallido de otro conflicto sucesorio semejante al que su padre había tenido que hacer frente décadas atrás ${ }^{24}$. Allí donde Fernando VI había fracasado, Carlos III había triunfado: el monarca tenía cuatro hijos varones (además del príncipe

${ }^{21} \mathrm{AHN}$, Estado, leg. 2464, s. f. Plenos poderes à los señores Marqueses de Grimaldi y de Montealegre para formalizar el Tratado Matrimonial de los ser[enísi ${ }^{m o s}$ Principes de Asturias, San Ildefonso, 14 de octubre de 1764. El texto no deja lugar a dudas de que se primaron los lazos dinásticos por encima del rango: «Casándole [al príncipe de Asturias] con la Serenísima Princesa de Parma [...] quién tiene por padre y madre nuestra misma sangre, circunstancia en que para n[uest]ro aprecio ninguna puede igualarla».

${ }^{22}$ Juan Martínez Cuesta, El infante don Gabriel de Borbón y Sajonia, mecenas ilustrado en la España de Carlos III (Valencia: Pre-Textos, 2003), 84.

${ }^{23}$ María Victoria López Cordón, "La construcción de una reina en la Edad Moderna, entre el paradigma y los modelos", en La reina Isabel y las reinas de España: realidad, modelos e imagen historiográfica, ed. María Victoria López Cordón y Gloria Franco Rubio (Madrid: Fundación Española de Historia Moderna, 2005), 311.

${ }^{24}$ Los ecos de la guerra de Sucesión se dejaban notar todavía en fechas tan lejanas como 1785. Ese año se produjo el matrimonio de Carlota Joaquina con el príncipe Juan de Portugal y la Gaceta de Madrid reproducía lo siguiente: «La experiencia de muchos siglos ha hecho ver a la Nación Española las revoluciones y desastres que causa la falta de sucesión legitima y la extinción de la varonía en la familia reynante. Llevado el Rey del amor paternal que profesa, a su fiel y generosa Nación al qual ella por su parte se ha hecho muy digna y acreedora, ha deseado siempre poner los medios posibles, y convenientes para libertarla en lo futuro de iguales o semejantes desgracias: y pareciéndole. el único con que en lo humano podría lograrse el de multiplicar su descendencia legítima». Gaceta de Madrid, no. 26, 1 de abril de 1785, 1. 
de Asturias, los infantes Gabriel, Antonio Pascual y Francisco Javier) y la próxima boda de los príncipes parecía asegurar la continuidad de la línea dinástica.

\section{LA NEGOCIACIÓN DEL ENLACE}

Luisa Isabel y Felipe de Parma ambicionaron importantes matrimonios para sus hijos. Estrechados en su minúsculo ducado, los duques deseaban mejores destinos de los que poseían. La duquesa viajaba frecuentemente a Versalles donde, con la connivencia de su padre, logró concertar el matrimonio de su hija mayor, Isabel, con el archiduque José, futuro José II. También apalabró las nupcias de su hija menor, María Luisa, con el duque de Borgoña ${ }^{25}$, hijo mayor del delfín Luis. Si bien este compromiso nunca fue anunciado públicamente, parece evidente que Luis XV y su hijo el delfín querían llevarlo a cabo. Coincidiendo con la muerte de Luisa Isabel, que se produjo en 1759, el heredero francés escribió a don Felipe, y Luis XV a Carlos III, informándoles de la conveniencia de educar a la joven princesa en Versalles ${ }^{26}$. Una posibilidad a la que el rey de España se negó con rotundidad, como constata la siguiente carta que escribió a su hermano:

si viesen que te quitábamos una hija para educarla, pues haciéndolo sería declararte nosotros mismos incapaz de hacerlo como debes, lo cual bien ves las malas consecuencias que traería, pues quien no es capaz de educar a sus hijos, tampoco lo es de ninguna otra $\operatorname{cosa}^{27}$.

La muerte del duque de Borgoña en 1761 puso fin al proyecto matrimonial que habría convertido a María Luisa de Parma en futura reina de Francia ${ }^{28}$. Sin embargo, las presiones de la corte francesa no se disiparon hasta $1762^{29}$. No obstante, Carlos III se había adelantado al monarca francés. Desde principios de 1760, fecha en la que aún vivía el duque de Borgoña, el monarca e Isabel de Farnesio comenzaron a mostrar un gran interés por María Luisa. La negativa de la corte española al traslado de la princesa a Versalles denota que el rey quizás pensaba ya en ella como posible consorte del príncipe Carlos. En septiembre de 1761 Carlos III advirtió al duque de Parma a este respecto: «Bien estoy seguro de que el secreto no saldrá de ti hasta que yo tea avise». ${ }^{30}$

${ }^{25}$ Luis José Javier de Borbón, duque de Borgoña (1751-1761), era el hijo varón mayor del delfín Luis Fernando. Como nieto primogénito de Luis XV estaba destinado a ser rey de Francia algún día. Sin embargo, falleció con apenas 10 años.

${ }^{26}$ Cayetano Mas Galvañ. "Los sentimientos en una relación regio-fraternal: Las cartas entre Carlos III y Felipe de Parma (1759-1765)”, en Comercio y Cultura en la Edad Moderna, ed. Juan José Iglesias Rodríguez, Rafael M. Pérez García y Manuel Francisco Fernández Chaves (Sevilla: Universidad de Sevilla, 2015), 2225.

${ }^{27}$ Ibídem, 2225.

${ }^{28}$ Casimir Stryiensky, Le gendre de Louis XV, Don Philippe, Infant d'Espagne et Duc de Parme (Paris: Colmann-Lévy, 1904), 469.

${ }^{29}$ Mas Galvañ, Los sentimientos, 2227.

${ }^{30}$ Ibídem, 2226-2227. 
La misiva dejaba claro que el acuerdo matrimonial se había llevado a cabo en secreto entre ambos hermanos. Ante las presiones de Versalles, Carlos III zanjó las pretensiones del rey de Francia al escribirle refiriéndose a María Luisa como «mi hija» ${ }^{31}$. Una sutil manera de anunciar a Luis XV que consideraba a la princesa como la prometida de su heredero.

Para entonces, había aparecido otro candidato a convertirse en esposo de María Luisa: el futuro emperador José II, quien pretendió la mano de la princesa tras el fallecimiento de su primera esposa, Isabel de Parma, en 1763. En cualquier caso, la posibilidad de que este enlace llegara a producirse fue desestimada en todo momento por Carlos III quien, según C. Cantú, rechazó los avances realizados en este sentido por la emperatriz María Teresa en nombre de su hijo ${ }^{32}$. La joven María Luisa, que tenía 14 años en el momento de sus nupcias con el príncipe de Asturias en 1765, habría podido convertirse en reina de Francia y emperatriz del Sacro Imperio, pero los azares del destino quisieron que ocupara el trono español.

Todos los historiadores coinciden en otorgar a Isabel de Farnesio un protagonismo esencial en la concertación del matrimonio del futuro Carlos IV. Pérez de Guzmán, autor de una serie de trabajos bastante favorables a María Luisa ${ }^{33}$, reprodujo en uno de sus artículos una hipotética conversación entre Carlos III y su madre que habría transcurrido en los siguientes términos: «Le tengo buscada novia, la hija de tu hermano Felipe. ¿María Luisa?, preguntó el rey. María Luisa tiene ya cumplidos los trece y las cartas que me escribe revelan su talento en su temprana discreción $\rangle^{34}$.

Aunque como acabamos de señalar es más que probable que esta conversación nunca tuviera lugar, o al menos no se reprodujera del modo en que la narra el autor, lo cierto es que tanto el marqués de Villaurrutia ${ }^{35}$ como, más recientemente, María Victoria López-Cordón ${ }^{36}$ insisten en que la mano de Isabel de Farnesio estuvo detrás de este enlace. La soberana seguía teniendo influencia sobre su hijo y los negocios de estado. Siendo Parma su antiguo estado patrimonial, probablemente la reina se encontraría en la obligación moral de procurar los mejores destinos a sus nietos. En cualquier caso, con independencia de consideraciones morales, las nupcias del príncipe de Asturias con María Luisa de Parma no sólo contribuían a reforzar la unidad entre

\footnotetext{
${ }^{31}$ Ibídem, 2227. 109.

${ }^{32}$ Cesare Cantù, "Isabella di Parma e la corte di Vienna", Archivio Storico Italiano, serie terza 50 (1868):

33 Antonio Calvo Maturana, María Luisa de Parma, reina de España, esclava del mito (Granada: Feminae, 2007), 228-232.

${ }^{34}$ Juan Pérez de Guzmán y Gallo, "Los encantos de la novia”, La España Moderna 303 (marzo de 1914): 43.

${ }^{35}$ Villaurrutia insiste en que el matrimonio se debió a la influencia de Isabel de Farnesio. Marqués de Villaurrutia, La Reina María Luisa, esposa de Carlos IV (Madrid: Francisco Beltrán, Librería española y extranjera, 1927), 18.

36 María Victoria López Cordón, "Reinas Madres, Reinas Hijas: Educación, Política y Correspondencia en las cortes dieciochescas", Historia y Política 31 (2014): 63. La historiadora sostiene que muerta Luisa Isabel de Borbón, Isabel de Farnesio se convirtió en el motor que trazó el destino de sus nietos.
} 
las distintas ramas de la Casa de Borbón sino también a favorecer el equilibrio de influencias entre las cortes de Viena y Madrid en la península itálica.

Elegida María Luisa de Parma por Carlos III como prometida de su hijo, el soberano se dispuso a iniciar los trámites matrimoniales y a concluirlos lo más pronto posible. El 21 de septiembre de 1764, nueve días antes de que Juan Domingo Pignatelli, plenipotenciario español en Parma fuera recibido por el duque para tratar los distintos aspectos relativos al matrimonio, Carlos III escribió una misiva a Luis XV informándole del enlace:

aunque Vuestra Majestad esté ya informado de mi decisión de casar a mi hijo con la princesa de Parma, el interés que ha demostrado por esta alianza no me permitía retrasar el comunicaros-que en Parma se firmará el contrato, que el matrimonio se hará público, y que [...] la misma escuadra que conducirá a mi hija a Italia, traerá a mi sobrina a España. Nuestro parentesco, nuestra unión, y la amistad que reina entre nosotros, hace que me plazca comunicaros lo antes posible mis [asuntos] familiares. Por ello, además de por el interés de Estado, he ordenado a mis ministros informar a los de Vuestra Majestad de aquellas [noticias] que afectan a nuestros reinos ${ }^{37}$.

Como puede apreciarse, Carlos III enmarcó el matrimonio del príncipe de Asturias en el contexto de los Pactos de Familia, según ponen de relieve sus alusiones al parentesco, unión y amistad que presidían las relaciones entre los titulares de las Coronas francesa y española ${ }^{38}$. No sólo eso, el monarca cumplía con su responsabilidad de informar a Luis XV, considerado cabeza de la Casa de Borbón, de las nupcias del heredero de una de las ramas de la dinastía borbónica ${ }^{39}$, y también obtenía de forma simbólica el consentimiento del monarca francés al matrimonio (aunque realmente todo estuviera ya negociado entre Carlos III y su hermano Felipe). El 30 de septiembre, Juan Domingo Pignatelli fue finalmente recibido oficialmente por el duque Felipe. El plenipotenciario español pudo asistir a la clase de baile de María Luisa e informó a Madrid que «está perfectamente bien hecha y me han asegurado que desde un mes a esta parte se reconocía que iba creciendo» ${ }^{40}$. Esta fue la primera información dada a la corte española sobre la salud de la princesa de Asturias, tema que mantendría en vilo a Carlos III más adelante.

${ }^{37}$ AHN, Estado, leg. 2473, no. 4. Carta de Carlos III a Luis XV, San Ildefonso, 21 de septiembre de 1764, Traducción del autor.

38 Ozanam, Dinastía, 17-19.

${ }^{39}$ El rey de Francia siempre fue sentido como la cabeza principal de todas las ramas de la familia Borbón. Ejemplo de ello es la carta que el embajador Ocariz presentó al ministro de exteriores francés durante la Revolución sobre la suerte de Luis XVI en el proceso que decidiría su suerte. El español insistía en que el juicio del jefe de la Casa de Borbón no podía ser visto como algo ajeno al rey de España. La carta se cita en: Andrés Muriel, Historia de Carlos IV, Carlos Seco Serrano, ed. (Madrid: Biblioteca de Autores Españoles, Atlas, 1959), 146.

${ }^{40}$ Laura García Sánchez. "Iconografía oficial e Imagen Real: Los Retratos de Juventud y de Pedida de la Princesa María Luisa de Parma", en Me veo luego existo: mujeres que representan, mujeres representadas, ed. Ester Alba Pagán y Luis Pérez Ochando (Madrid: CSIC, 2015), 133. 
Quedaba la parte más complicada del enlace: la formalización de las capitulaciones matrimoniales. Para llevar a cabo las negociaciones con Parma, el rey y el príncipe firmaron poderes para que el marqués de Grimaldi, secretario de estado, gestionara las negociaciones con el marqués de Montealegre, plenipotenciario del duque de Parma, aunque realmente el peso de este trámite recayó sobre Guillaume Du Tillot, principal ministro de Felipe I. Pignatelli y Montealegre quedaban por tanto relegados a la condición de meros informadores en la corte parmesana.

El interés de Grimaldi en el contenido de las capitulaciones fue absoluto, según constatan los diferentes tachones que incluye su correspondencia a este respecto. Antes de redactar la versión definitiva del acuerdo, el secretario elaboró varias minutas en las que estudiaba dónde había de celebrarse el matrimonio, cómo debía ser tratada la princesa en caso de que Parma acogiera la boda por poderes, qué dote se otorgaría a María Luisa, así como la pensión y joyas que debía de recibir por parte de su futuro esposo. Además, Grimaldi también se preocupó por quién debería afrontar los gastos del viaje y acordó que el duque debía hacer entrega de su hija a los miembros de su futura servidumbre española en Génova ${ }^{41}$. Queriendo tener un modelo en el que basarse, el secretario de estado pidió a Du Tillot una copia del contrato matrimonial de Isabel de Parma y José $\mathrm{II}^{42}$. El día 15 de octubre, el marqués de Montealegre y Grimaldi firmaron como plenipotenciarios el acuerdo. Se estableció que María Luisa recibiría una dote de cien mil doblas de oro y tendría que renunciar a sus derechos sucesorios sobre el ducado de Parma ${ }^{43}$.

Ultimado el contrato matrimonial, restaba solicitar la dispensa pontificia debido al estrecho parentesco de los contrayentes, tal y como establecía el primer artículo de las capitulaciones ${ }^{44}$. En relación a este punto, Grimaldi escribió a Du Tillot para que el duque Felipe enviara una carta al Papa, al mismo tiempo que el rey ${ }^{45}$, requiriendo el permiso pontificio y así ambas cortes actuaran a la par ${ }^{46}$. Carlos III deseaba la pronta resolución de este asunto: «Cuide v.s de solicitar y recoger esta [se

${ }^{41} \mathrm{AHN}$, Estado, leg. 2464, s. f. Minuta de varias preguntas con la respuesta interlineal de mano de S.E [xcelenci $]^{a}$ el S [eño]r Mar[que]s de Grimaldi pertenecientes a la celebridad del Matrimonio, Tratamiento, viage Dote, Pension etc de la Ser[enisi $]^{\text {ma }}$ Princesa D [oñ] Luisa Maria.

42 AHN, Estado, leg. 2464, s. f. Carta de Guillaume Du Tillot al marqués de Grimaldi, Parma, 26 de agosto de 1764 .

${ }^{43} \mathrm{AHN}$, Estado, leg. 2464, s. f. Tratado Matrimonial del Ser[enísi]mo Principe de Asturias D. Carlos n[uest]ro señor con La ser[enísi] ${ }^{m a}$ S [eño] $]^{r a}$ Princesa de Parma D [oñ] $]^{a}$ Luisa Maria, San Ildefonso, 15 de octubre de 1764. En el artículo segundo se especificaba el pago de la dote y en el cuarto la renuncia a los derechos dinásticos de María Luisa sobre Parma.

44 AHN, Estado, leg. 2464, s.f. El artículo refería: «se celebren [...] Desposorios con el serenísimo Principe de Asturias $\mathrm{D}[\mathrm{o}]^{\mathrm{n}}$ Carlos, mediante la gracia de Dios todo poderoso, y la Dispensacion del Sumo Pontifice, que hace necesaria su parentesco».

${ }^{45}$ AHN, Estado, leg. 2521, no. 26. Carta de Carlos III a Clemente XIII, San Ildefonso, 16 de octubre de 1764.

46 AHN, Estado, leg. 2521, no. 28. Carta del Marqués de Grimaldi a Guillaume Du Tillot, San Ildefonso, 16 de octubre de 1764. 
refiere a la dispensa] con la [mayor] brevedad posible y de enviarla, que así me manda el Rey se le prevenga» ${ }^{47}$.

El embajador español en Roma, Manuel de Roda, cumplió en menos de un mes las órdenes del rey y remitió a Madrid la necesaria dispensa en noviembre de 1764. No obstante, una vez concluidas sus gestiones, el diplomático advirtió a Grimaldi que había excluido de las mismas a Don Felipe $^{48}$.

La preocupación de Roda en este punto radicaba en la posibilidad de que el Papa se negara a responder a una carta firmada por Don Felipe como duque de Parma, territorio feudatario de la Santa Sede y del que el infante no había sido reconocido como soberano por el pontífice. A la postre, el duque no cuestionó el quehacer de Roda y Du Tillot le escribió autorizándole a hacer lo que considerara más oportuno con la carta, advirtiéndole, eso sí, de que si no se la entregaba al pontífice la remitiera de nuevo a Parma ${ }^{49}$.

No se equivocaba Roda en cuanto a que el Papa negaría el título ducal a don Felipe pues la dispensa comenzaba:

Dilectissimo in Christo Filio nostro Carolo Antonio infanti Asturiae Principi Charissimi in Christo Fily nostri Caroli Hispaniarum Regis Catholici, et Dilectissimae in Christo Filiae nostrae Aloysiae, seu Ludovicae Mariae dilectissimi in Christo Filii nostri Philippi, Hispaniarum infantis respective natis ${ }^{50}$.

La habilidad diplomática del embajador español permitió así salvar un escollo que habría dificultado la resolución del matrimonio.

\section{CONOCERSE DESDE LA DISTANCIA: INTERCAMBIO DE RETRATOS Y AJUAR}

Solucionados los trámites burocráticos, Carlos III pudo dirigirse al fin a la que iba a ser su nuera, a la que comunicó su anhelo por tenerla junto a él lo más pronto posible $^{51}$.

\footnotetext{
${ }^{47}$ AHN, Estado, leg. 2521, no. 27. Carta del Marqués de Grimaldi a Manuel de Roda, San Ildefonso, 16 de octubre de 1764.

48 AHN, Estado, leg. 2521, no. 29. Carta de Manuel de Roda al marqués de Grimaldi, Roma, 8 de noviembre de 1764.

${ }^{49}$ AHN, Estado, leg. 2521, no. 20. Carta de Guillaume Du Tillot al marqués de Grimaldi, Parma, 11 de noviembre de 1764 .

50 AHN, Estado, leg. 2521, no. 31. Dispensa de Clemente XIII autorizando el matrimonio entre el príncipe Carlos y María Luisa de Parma, Roma, 6 de noviembre de 1764.

51 AHN, Estado, leg. 2521, no. 37. Carta de Carlos III a María Luisa de Parma, San Lorenzo del Escorial, 28 de noviembre de 1764. Decía así: «Querida sobrina mia. [...] contemplo tu ajustado casamiento con mi querido Hijo Carlos, quien tiene la discreción que manifiestas, y la virtud q no ignoro, es preciso sea un t[iempo] la delicia del Principe y el consuelo de su Padre. Con esta agradable imaginación pasare contento los días que he de tardar en verte; y como los cuento, se mui bien que el 9. del mes proximo es el de tu cumpleaños. Lograle mui feliz y alegre: que assi te lo anuncia y desea el tierno amor de tu tio».
} 
En las semanas siguientes, las cortes de Parma y Madrid dieron inicio a una actividad frenética pues había que comenzar a organizar el viaje de la princesa de Asturias. Don Felipe y Du Tillot se concentraron en preparar un magnífico ajuar para María Luisa. Además de entregarle las cien mil doblas de dote ya mencionadas, el duque se preocupó porque su hija contara con un guardarropa y unas joyas dignas de la nieta de los reyes de España y Francia. En materia de gusto e influencias culturales, Parma se encontraba bajo la órbita francesa. Por tanto, no es extraño que el ajuar de María Luisa se confeccionara en París. Du Tillot y Claude Bonet, tesorero de Don Felipe, fueron los encargados de ejecutar las órdenes del duque. No sin dificultad debido a la premura del tiempo, ambos lograron proveer a la princesa de diferentes vestidos adquiridos a los marchantes de moda Borurjut, Buffaut y Le Roux, quienes dispusieron de un maniquí con las medidas exactas de María Luisa ${ }^{52}$. En cuanto a las joyas, se debieron a Pierre André Jacquemin ${ }^{53}$.

Además del ajuar paterno, María Luisa recibió de Carlos III joyas por valor de cincuenta mil escudos ${ }^{54}$. Antes incluso de que tuviera lugar la firma del contrato matrimonial, el rey de España encargó un espléndido conjunto de joyas para su futura nuera, al igual que hiciera con su hija, la infanta María Luisa, casada con el gran duque de Toscana. En agosto de 1764, a través del marqués de Grimaldi, Carlos III ordenó al joyero parisino Laborde la realización de los diseños correspondientes a cuatro aderezos de joyas que debían ser remitidos a Madrid. Una vez recibidos, correspondió al platero real, Francisco Sáez, la definitiva ejecución de las distintas piezas, en concreto de un peto, un collar, una pareja de pendientes, una piocha, un bonetillo, dos pulseras, dos sortijas, lazos de mangas, piezas de costados y un lazo de falda cuyo coste ascendió a 142.569 pesos $^{55}$. Los miembros de la familia real francesa ofrecieron también distintas joyas a María Luisa con motivo de su matrimonio. Sus abuelos, Luis XV y María Leczinska, regalaron a la princesa un retrato esmaltado en brillantes y una aigrette de diamantes respectivamente; el delfín Luis una sortija con un enorme brillante blanco; su esposa, María Josefa de Sajonia, un lazo de cabeza, y Madame Adelaida, la mayor de las hijas solteras del monarca francés, unos pendientes ${ }^{56}$.

Tal y como marcaba la tradición, también se dispuso que los futuros esposos intercambiaran sus respectivos retratos con el fin de que pudieran hacerse una idea lo más aproximada posible de su apariencia física. Tras una serie de infructuosos intentos

52 Pilar Benito García, “Aproximación al guardarropa de María Luisa de Parma”, Reales Sitios 175 (2008): 48-52.

53 Henry Bedarida, Parma e la Francia, 1748-1789 (Milán: FMR, 1985), 204 y 224.

54 Según el artículo V de su contrato matrimonial a María Luisa le correspondían joyas por valor de cincuenta ml escudos.

55 Amelia Aranda Huete. "Las joyas de la reina María Luisa de Parma, esposa de Carlos IV", en Estudios de Platería, San Eloy 2007, ed. Jesús Rivas Carmona (Murcia: Servicio de Publicaciones de la Universidad de Murcia, 2007), 22. La forma de proceder del rey no era rara en España. La familia real encargaba los diseños de sus joyas en París, referencia indiscutible en cuanto a tendencias de moda y joyería durante el siglo XVIII. Sin embargo, con el fin de economizar, solían ser artesanos ligados a la corte española quienes llevaban a cabo las piezas finales. De este modo, se eludían los elevados precios que los joyeros parisinos adjudicaban a sus exclusivas realizaciones.

${ }^{56}$ Ibídem, 24. 
que no satisficieron a la propia María Luisa, quien confesó encontrar poco parecido entre su fisonomía y el resultado final del pintor ${ }^{57}$, el duque Felipe ordenó en enero de 1765 a Laurent Pecheux que se trasladara a Parma con el fin de retratar a su hija. Destacado retratista de la Escuela de Mengs, el espectacular lienzo de Pecheux muestra a la joven princesa en una lujosa estancia en la que sobresalen una consola de mármol, sobre la que reposa un elaborado reloj de bronce, y un magnífico sillón, casi un trono, que evoca su futuro como reina de España. María Luisa, que luce un vestido de brocado a rayas y la condecoración de la orden de la Cruz Estrellada en el pecho, porta en su mano derecha una caja esmaltada que alberga el retrato de su futuro esposo ${ }^{58}$. El resultado definitivo, que llevó al pintor tan solo cuarenta días, asombró a la corte de Parma debido a que tenía exactamente la misma altura que la retratada, según constató el propio duque Felipe, quien midió tanto a su hija como a la propia pintura ${ }^{59}$. También complació a Pignatelli, quien en una carta a Grimaldi alabó la maestría de Pecheux al plasmar los rasgos de María Luisa ${ }^{60}$ (Fig. 1).

El retrato fue enviado a España a finales de marzo de 1765. Tras una serie de demoras causadas por las tareas de embalaje, debió llegar a Madrid en torno al 28 de abril de ese mismo año. Aunque a lo largo del viaje el lienzo sufrió distintos desperfectos que tuvieron que ser reparados por Mengs ${ }^{61}$, el propio Pecheux reconoce en sus Memorias que la pintura mereció la admiración y los aplausos de Carlos III $^{62}$. Un segundo retrato de María Luisa sería enviado también a Madrid, probablemente aquel cuyo resultado no agradó a la retratada. Obra de Giuseppe Baldrighi, retratista oficial de la corte de Parma, muestra a la princesa ataviada con un rico vestido de color rosa con adornos de encaje blanco y portando una discreta peluca sobre la que luce una flor ${ }^{63}$ (Fig. 2).

57 Almudena Ros de Barbero, "Laurent Pecheux: Pintor francés retratista de María Luisa de Parma, princesa de Asturias", en El arte foráneo en España, presencia e influencia, ed. Miguel Cabañas Bravo (Madrid: CSIC, 2005), 409.

${ }^{58}$ García Sánchez, Iconografía, 134-135.

${ }^{59}$ Ros de Barbero, Laurent Pecheux, 409.

${ }^{60}$ José Manuel de la Mano. "Hacia las parejas reales de Goya, evolución de la iconografía oficial de Carlos IV y María Luisa de Parma a través de sus pintores de cámara”, en Carlos IV, mecenas y coleccionista, ed. Javier Jordán de Urríes y de la Colina y José Luis Sancho (Madrid: Patrimonio Nacional, 2009), 77 78.

${ }^{61}$ Ros de Barbero, Laurent Pecheux, 409.

${ }^{62}$ De la Mano, Hacia las parejas, 77.

${ }^{63}$ Benito García, P. "María Luisa de Parma", en El Retrato en las colecciones reales, ed. Carmen García Frías Checa y Javier Jordán de Urríes y de la Colina (Madrid: Patrimonio Nacional, 2014), 370-373. 


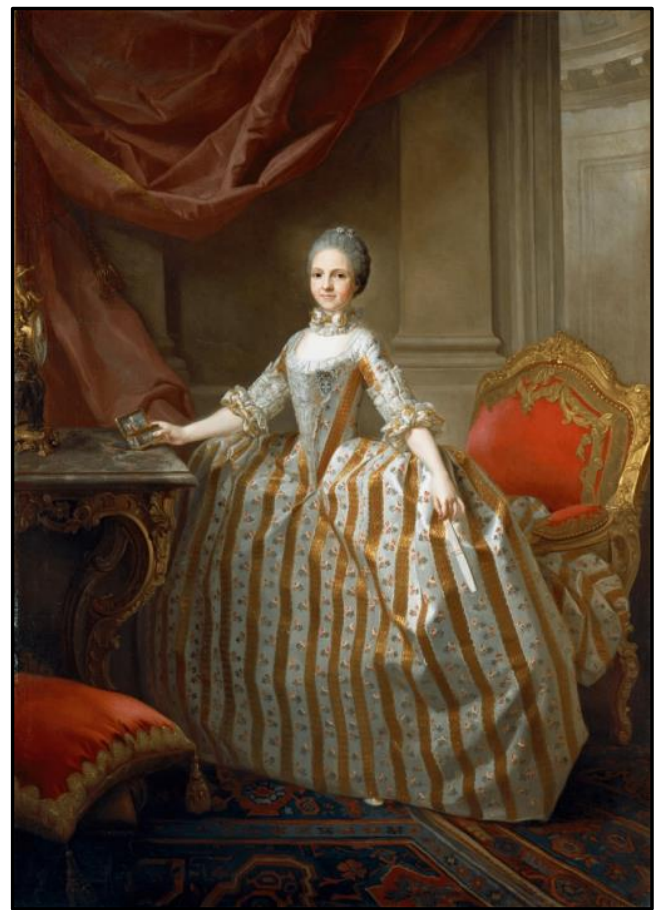

Fig. 1- Laurent Pecheux, Retrato de pedida de María Luisa de Parma. 1765, Nueva York, Metropolitan Museum.

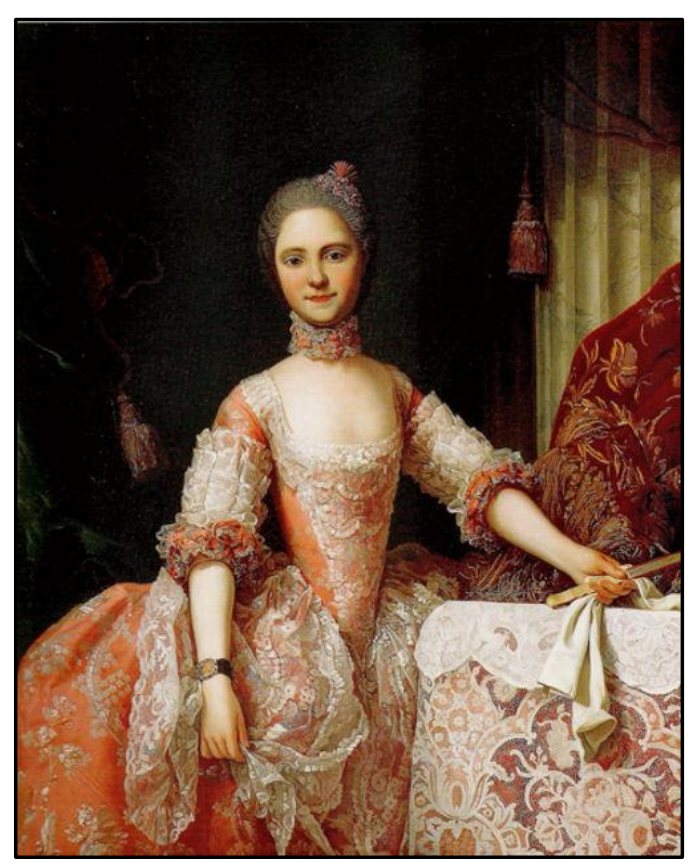

Fig. 2- Giuseppe Baldrigui, Retrato de pedida de María Luisa de Parma, 1765, Patrimonio Nacional, Palacio Real de El Pardo. 
Al mismo tiempo se remitió a Parma el retrato del príncipe de Asturias, don Carlos, realizado por Mengs, pintor de cámara de Carlos III y uno de los mejores pinceles de la corte española en aquel momento. En él, el príncipe luce el mismo traje que llevaría la noche de su matrimonio con María Luisa, compuesto de casaca y chupa bordadas en oro; sobre su pecho, porta las máximas Órdenes de caballería de la Casa de Borbón: el Toisón de Oro español; la francesa Orden del Santo Espíritu y la napolitana Orden de San Genaro. En su mano sostiene un libro abierto en el que se puede leer el nombre de su futura esposa, Luisa. Sobre el tablero de mármol de una consola que se encuentra a su lado, descansan unos libros y unas hojas, con anotaciones de geometría, que dan cuenta de los intereses intelectuales del joven heredero, perfecto príncipe ilustrado ${ }^{64}$ (Fig. 3).

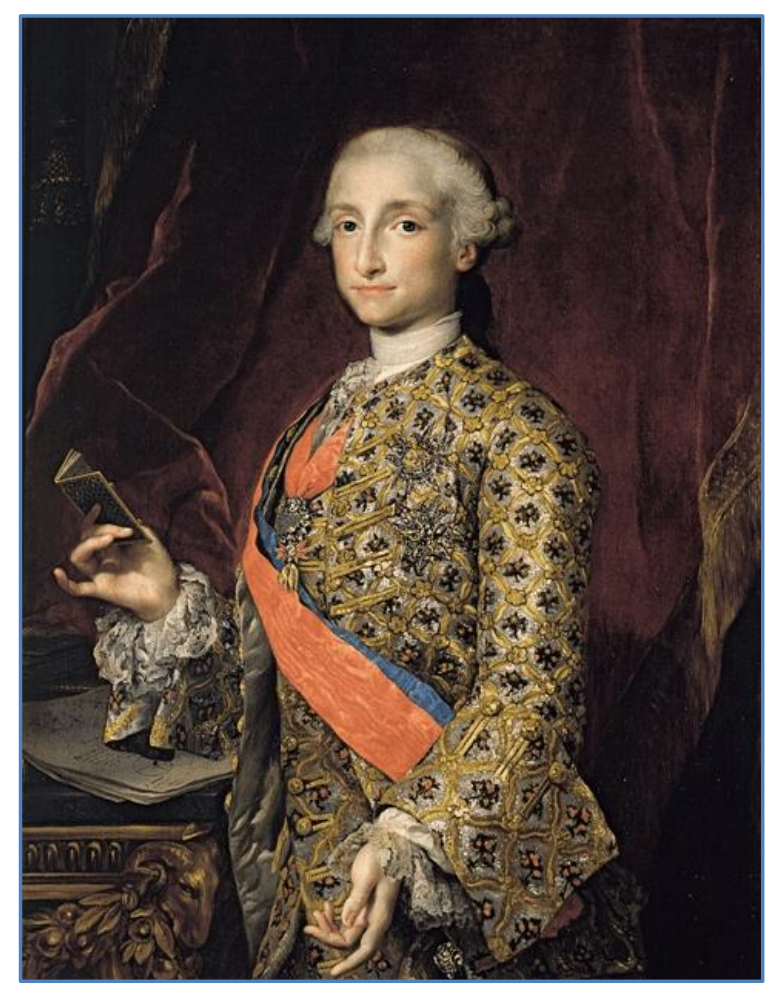

Fig. 3- Anton Raphael Mengs, Carlos Antonio de Borbón, príncipe de Asturias. 1765, Parma, Galleria Nazionale. Fuente: https://www.revistadearte.com/2009/05/17/carlos-antonio-de-borbon-principede-asturias/

Los retratos mencionados representaban la corporeidad pictórica de los desposados. El cuerpo de los soberanos era dual, uno era físico y otro inmaterial,

${ }^{64}$ Javier Jordán de Urriés y de la Colina, "Carlos Antonio de Borbón, príncipe de Asturias", en Carlos IV, mecenas y coleccionista, ed. Javier Jordán de Urríes y de la Colina y José Luis Sancho (Madrid: Patrimonio Nacional, 2009), 136-137. 
símbolo de la perdurabilidad de la monarquía ${ }^{65}$. Carlos III, consciente de la importancia de la propaganda regia, decidió explotar al máximo la imagen de los herederos de la Corona. Para ello encargó a Mengs la ejecución de dos nuevos retratos que se convertirían en la imagen oficial de los príncipes de Asturias durante casi veinte años. El pintor representó al futuro Carlos IV en traje de caza, una de sus principales aficiones, junto a un mastín y portando, como no podía ser de otra manera, una escopeta. En el pecho, de nuevo luce la Orden del Toisón (Fig. 4). La pintura de María Luisa la muestra en los jardines del Palacio de Aranjuez, ataviada con un riquísimo traje con diseños florales estampados junto a algunas de las joyas que recibiera de su esposo, así como la Orden de la Cruz Estrellada, que lleva prendida en el pecho. En su mano izquierda porta dos flores, mientras que, con la derecha, en cuya muñeca destaca una pulsera de triple vuelta de perlas con la efigie del príncipe rodeada de brillantes, sostiene un abanico guarnecido de diamantes ${ }^{66}$. Desde un punto de vista general, ambos retratos expresan el interés de la Ilustración en diferenciar los roles y espacios de actuación de uno y otro sexo. El príncipe aparece en el bosque, dispuesto a desarrollar una actividad física, la caza, que estimulaba el desarrollo de virtudes y destrezas propiamente masculinas, como la templanza, la fuerza y el coraje. Por su parte, María Luisa lo hace en un entorno casi bucólico y propiamente cortesano; rodeada de naturaleza y en una actitud que denota la relajación que deriva del cultivo de una afición tan femenina como masculina es la del príncipe: pasear y deleitarse en el aroma de las flores ${ }^{67}$ (Fig. 5).

${ }^{65}$ Ernest. H. Kantorowickz, Los dos cuerpos del rey. Un estudio de teología política medieval (Madrid: Alianza, 1985).

${ }^{66}$ Javier Jordán de Urriés y de la Colina, "Las casitas de Carlos IV", en Actas de las Jornadas de Arte e Iconografía sobre Carlos IV y el arte de su reinado, ed. Alfonso Rodríguez G. De Ceballos y Ângel Rodríguez Rebollo (Madrid: Fundación Universitaria Española, 2011), 98.

${ }^{67}$ Pilar Benito García. "María Luisa de Parma con mantilla", en El Retrato en las colecciones reales, ed. Carmen García Frías Checa y Javier Jordán de Urríes y de la Colina (Madrid: Patrimonio Nacional, 2014), 389. 


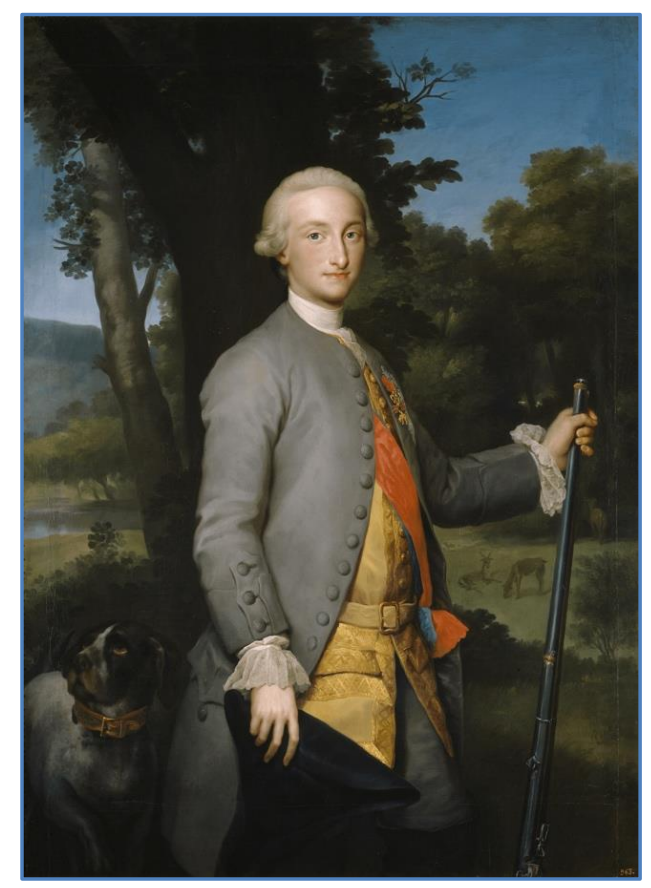

Fig. 4- Anton Raphael Mengs, Carlos Antonio de Borbón, príncipe de Asturias en traje de cazador. 1765, Madrid, Museo del Prado.

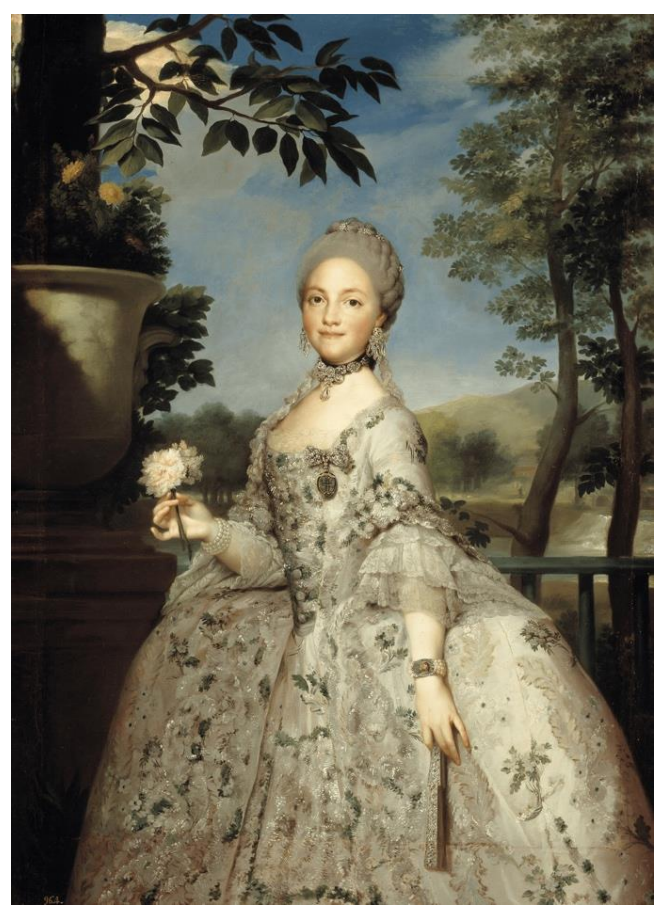

Fig. 5- Anton Raphael Mengs, María Luisa de Parma, princesa de Asturias. 1765, Madrid, Museo del Prado. 
Junto a los retratos a los que acabamos de referimos, Carlos III ordenó en la primavera de 1765 a Francisco Tomás Prieto, director de la Real Casa de la Moneda, la acuñación de la medalla que conmemoraría el matrimonio de su hijo. La litografía de esta obra, realizada por Manuel Salvador Carmona y que podía adquirirse en un establecimiento de la calle Carretas, tuvo indudablemente una mayor difusión que el resto de la producción artística ligada al enlace de los príncipes de Asturias y contribuyó a divulgar su imagen dentro y fuera de las fronteras de la Monarquía. Por lo que respecta a la medalla, puede considerarse una obra maestra, pues aunó la excelencia de Mengs, al que se deben las efigies del futuro Carlos IV y su esposa, con la pericia grabadora de Prieto. En el reverso de la moneda aparece un Carlos III muy idealizado y rejuvenecido, de inspiración francesa, cuyo busto rodea la leyenda Parens Optimus. En su anverso, encontramos a los herederos, junto a la leyenda Publicae Felicit Pignus. Presente y futuro de la dinastía se muestran juntos, en perfecta harmonía, como garantía de estabilidad monárquica y felicidad pública, fin último al que debían aspirar todos los soberanos ilustrados ${ }^{68}$ (Fig. 6).

\section{EPÍLOGO}

La ya princesa de Asturias iniciaría su viaje nupcial hacia España el 29 de junio de 1765. Abandonó su Parma natal con destino a Génova donde embarcaría en la flota española que la trasladaría a la península ${ }^{69}$. María Luisa de Parma entró en su país de adopción vía Cartagena ${ }^{70}$ y llegó el 4 de septiembre a San Ildefonso donde contraería matrimonio con el futuro Carlos IV la misma noche de su arribo. Posteriormente se celebrarían unas espléndidas fiestas en Madrid con motivo de las nupcias. El periplo coincidió con el también viaje nupcial de su prima, la infanta María Luisa, que como hemos reseñado anteriormente casaría con el archiduque Leopoldo, futuro gran duque de Toscana y sucesor de José II como emperador del Sacro Imperio entre 1790 y 1792. Las jóvenes realizarían un viaje a la inversa, siendo protagonistas de un doble intercambio de princesas, algo muy común en las monarquías del Antiguo Régimen ${ }^{71}$.

${ }^{68}$ Elvira Villena, "Medalla conmemorativa del matrimonio del príncipe Carlos de Borbón y María Luisa de Parma" en Carlos IV, mecenas y coleccionista, ed. Javier Jordán de Urríes y de la Colina y José Luis Sancho (Madrid: Patrimonio Nacional, 2009), 142-143.

${ }^{69}$ Laura García Sánchez, "Fiesta y ceremonial de las cortes de Génova y Madrid: Llegada y celebración del matrimonio de la nueva princesa de Asturias, María Luisa de Parma, en 1765”, Boletín de Arte 20 (1999): 167-180.

${ }^{70}$ Sobre el importante papel que jugó el reino de Murcia en el viaje nupcial de María Luisa de Parma: Sergio Belmonte Hernández, "Del olor de los mástiles al olor de la fiesta: La egregia llegada de María Luisa de Parma a España” (Trabajo fin de Máster inédito, Universidad Complutense de Madrid, 2020).

${ }^{71}$ Una panorámica completa de la negociación de los matrimonios, los viajes nupciales y las fiestas ejecutadas se realizará en mi proyecto de Tesis Doctoral titulado: "Los dobles matrimonios de 1765: Los viajes nupciales de la infanta María Luisa de Borbón y la princesa María Luisa de Parma”, dirigida por los profesores Carmen Sanz Ayán y José Antonio López Anguita. 


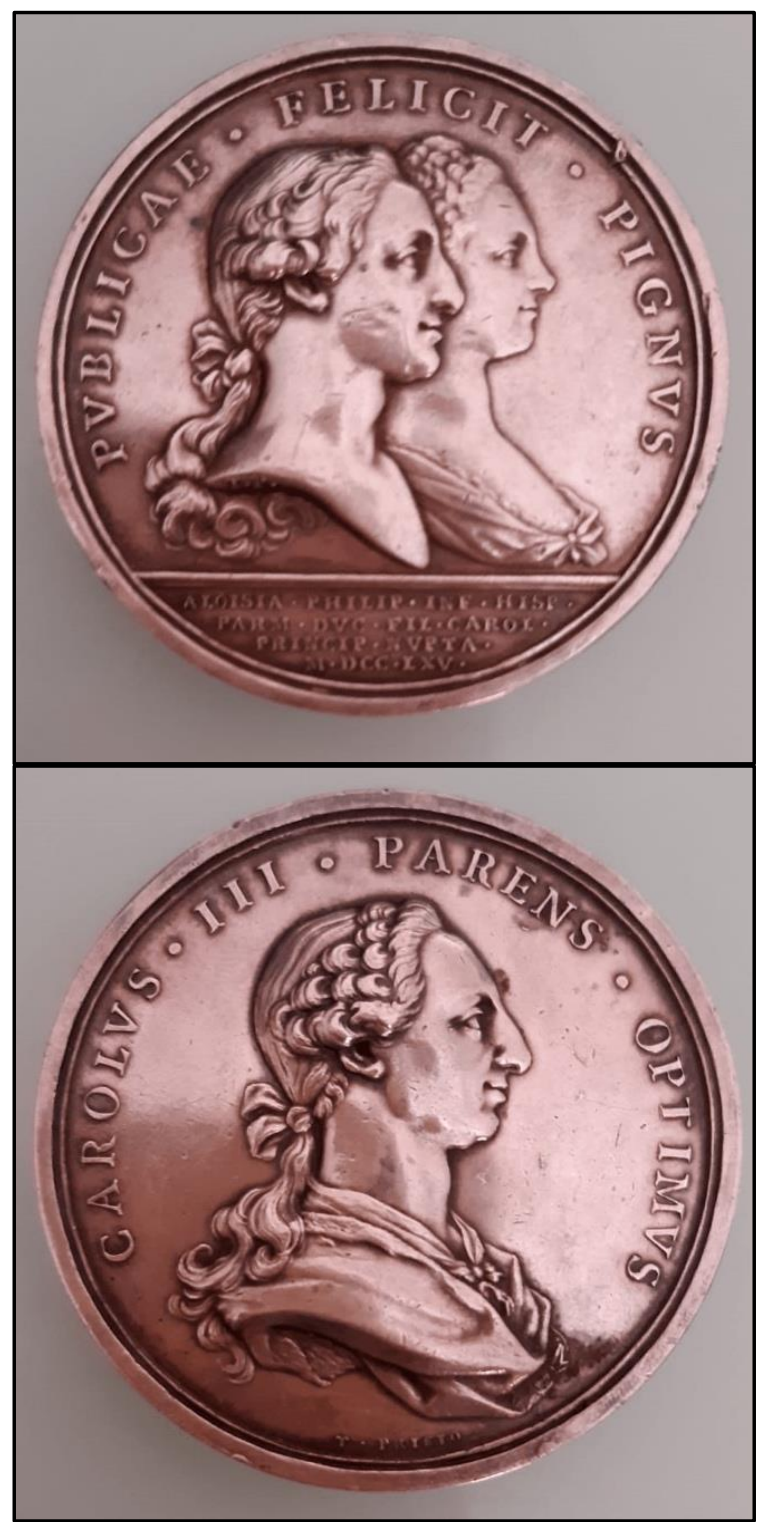

Fig. 6- Tomás Francisco Prieto, Medalla nupcial de los príncipes de Asturias Carlos y María Luisa. 1765. Colección personal del autor. 


\section{REFERENCIAS BIBLIOGRÁFICAS}

Amelia Aranda Huete. "Las joyas de la reina María Luisa de Parma, esposa de Carlos IV”, en Estudios de Platería, San Eloy 2007, ed. Jesús Rivas Carmona (Murcia: Servicio de Publicaciones de la Universidad de Murcia, 2007), 21-40.

Françoise Autrand, Lucien Bély, Philippe Contamine. y Thierry Lentz, eds., Histoire de la diplomatie française. I: Du Moyen Age à l'Empire (París: Perrin, 2007).

Elisabeth Badinter, Je meurs d amour pour toi lettres a l'archiduchesse Marie-Christine (Paris: Tallandier, 2008).

Sergio Belmonte Hernández, "Del olor de los mástiles al olor de la fiesta: La egregia llegada de María Luisa de Parma a España” (Trabajo fin de Máster inédito, Universidad Complutense de Madrid, 2020).

Pilar Benito García, “Aproximación al guardarropa de María Luisa de Parma”, Reales Sitios 175 (2008): 46-67.

—, "María Luisa de Parma con mantilla", en El Retrato en las colecciones reales, ed. Carmen García Frías Checa y Javier Jordán de Urríes y de la Colina (Madrid: Patrimonio Nacional, 2014), 388-389.

Henry Bedarida, Parma e la Francia, 1748-1789 (Milán: FMR, 1985).

Rohan Butler. "The secret compact of 1753 between the kings of France and Naples", en Royal and Republican Sovereignty in Early Modern Europe: Essays in memory of Ragnhild Hatton, ed. Robert Oresko, G. C. Gibbs y Hamish Scott (Cambridge: Cambridge University Press, 1997), 551-579.

Antonio Calvo Maturana, María Luisa de Parma, reina de España, esclava del mito (Granada: Feminae, 2007).

Cesare Cantù, "Isabella di Parma e la corte di Vienna", Archivio Storico Italiano, serie terza 50 (1868): 89-120.

Rosa María Capel Martínez y José Cepeda Gómez, eds., El siglo de las luces, política y sociedad (Madrid: Síntesis, 2006).

Jean Paul Desprat, Le Cardinal de Bernis 1715-1794. La Belle Ambition (París: Perrin, 2000).

Conde de Fernán Núñez, Vida de Carlos III. Alfred Morel Fatio y Antonio Paz y Meliá, eds. (Madrid: Librería de los Bibliófilos, Fernando Fé, 1898). 
Laura García Sánchez, "Iconografía oficial e Imagen Real: Los Retratos de Juventud y de Pedida de la Princesa María Luisa de Parma", en Me veo luego existo: mujeres que representan, mujeres representadas, ed. Ester Alba Pagán y Luis Pérez Ochando (Madrid: CSIC, 2015), 129-140.

—, "Fiesta y ceremonial de las cortes de Génova y Madrid: Llegada y celebración del matrimonio de la nueva princesa de Asturias, María Luisa de Parma, en 1765", Boletin de Arte 20 (1999): 167-180.

José Luis Gómez Urdáñez, Fernando VI (Madrid: Arlanza, 2001).

Juan Pérez de Guzmán y Gallo, "Los encantos de la novia”, La España Moderna 303 (marzo de 1914): 42-52.

Pieter M. Judson, The Habsburg Empire. A new history (Cambridge, Massachusetts, Londres: The Belknap Press of Harvard University Press, 2016).

Ernest. H. Kantorowickz, Los dos cuerpos del rey. Un estudio de teología política medieval (Madrid: Alianza, 1985).

María Victoria López Cordón, "Reinas Madres, Reinas Hijas: Educación, Política y Correspondencia en las cortes dieciochescas", Historia y Politica 31 (2014): 4980.

-, "La construcción de una reina en la Edad Moderna, entre el paradigma y los modelos", en La reina Isabel y las reinas de España: realidad, modelos e imagen historiográfica, ed. María Victoria López Cordón y Gloria Franco Rubio (Madrid: Fundación Española de Historia Moderna, 2005), 309-338.

-, "Pacte de Famille ou interets d'Etat? La monarchie française et la diplomatie espagnole du XVIIIe siècle", en La présence des Bourbons en Europe XVIe-XXIe siècle, ed. Lucien Bély (París: Presses Universitaires de France, 2000), 185-205.

José Manuel de la Mano, "Hacia las parejas reales de Goya, evolución de la iconografía oficial de Carlos IV y María Luisa de Parma a través de sus pintores de cámara", en Carlos IV, mecenas y coleccionista, ed. Javier Jordán de Urríes y de la Colina y José Luis Sancho (Madrid: Patrimonio Nacional, 2009), 75-95.

Juan Martínez Cuesta, El infante don Gabriel de Borbón y Sajonia, mecenas ilustrado en la España de Carlos III (Valencia: Pre-Textos, 2003).

Marqués de Villaurrutia, La Reina María Luisa, esposa de Carlos IV (Madrid: Francisco Beltrán, Librería española y extranjera, 1927). 
Cayetano Mas Galvañ, "Los sentimientos en una relación regio-fraternal: Las cartas entre Carlos III y Felipe de Parma (1759-1765)", en Comercio y Cultura en la Edad Moderna, ed. Juan José Iglesias Rodríguez, Rafael M. Pérez García y Manuel Francisco Fernández Chaves (Sevilla: Universidad de Sevilla, 2015), 2215-2229.

William J. McGill, “The Roots of Policy: Kaunitz in Vienna and Versailles, 1749-1753”, Journal of Modern History 2 (1971): 228-244.

Andrés Muriel, Historia de Carlos IV, Carlos Seco Serrano, ed. (Madrid: Biblioteca de Autores Españoles, Atlas, 1959)

Didier Ozanam, "Dinastía, Diplomacia y Política Exterior", en Los Borbones, Dinastía y Memoria de nación en la España del siglo XVIII, ed. Pablo Fernández Albaladejo (Madrid: Marcial Pons, 2000), 17-46.

—, "La Crisis de las Relaciones Hispano-Francesas a mediados del Siglo XVIII. La Embajada de Jaime Masones de Lima (1752-1761)", Tiempos Modernos 5, no. 14 (2006), http://www.tiemposmodernos.org/tm3/index.php/tm/article/view/101/13 $\underline{4}$ (consultado el 5 de junio de 2020).

Almudena Ros de Barbero. "Laurent Pecheux: Pintor francés retratista de María Luisa de Parma, princesa de Asturias", en El arte foráneo en España, presencia e influencia, ed. Miguel Cabañas Bravo (Madrid: CSIC, 2005), 407-416.

Henry Sage, "Les ambitions de Louise-Élisabeth de France, duchesse de Parme, ses intrigues a la cour de Versailles", Annales de Sciences Politiques 18 (1903): 686-701.

Elisabetta De Santi Gentili, "Il viaggio verso Napoli della regina Maria Carolina d'Asburgo nel 1768: il passaggio nella Tuscia" (Tesis Doctoral, Università degli studi della Tuscia, 2002).

Casimir Stryiensky, Le gendre de Louis XV, Don Philippe, Infant d'Espagne et Duc de Parme (Paris: Colmann-Lévy, 1904).

Javier Jordán de Urriés y de la Colina, "Carlos Antonio de Borbón, príncipe de Asturias", en Carlos IV, mecenas y coleccionista, ed. Javier Jordán de Urríes y de la Colina y José Luis Sancho (Madrid: Patrimonio Nacional, 2009), 136-137.

-, "Las casitas de Carlos IV", en Actas de las Jornadas de Arte e Iconografía sobre Carlos IV y el arte de su reinado, ed. Alfonso Rodríguez G. De Ceballos y Ángel Rodríguez Rebollo (Madrid: Fundación Universitaria Española, 2011), 95-116. 
Pablo Vázquez Gestal, Una nueva majestad, Felipe V, Isabel de Farnesio y la identidad de la Monarquia (Madrid: Marcial Pons, Fundación de Municipios Pablo de Olavide, 2013).

José Juan Vidal y Enrique Martínez Ruíz, eds., Política interior y exterior de los Borbones (Barcelona: Tres Cantos, Istmo, 2001).

Elvira Villena, "Medalla conmemorativa del matrimonio del príncipe Carlos de Borbón y María Luisa de Parma" en Carlos IV, mecenas y coleccionista, ed. Javier Jordán de Urríes y de la Colina y José Luis Sancho (Madrid: Patrimonio Nacional, 2009), 142-143.

Recibido: 28 de septiembre de 2020

Aceptado: 5 de diciembre de 2020 